\title{
ChARACTERIZING PATTERNS IN STUDENT ENGAGEMENT IN A TEAM-BASED AND PROJECT-CENTRIC COURSE
}

\author{
Roza Ghaemi ${ }^{1}$ and Gabrielle Lam ${ }^{1,2}$ \\ ${ }^{1}$ School of Biomedical Engineering and ${ }^{2}$ Department of Materials Engineering \\ University of British Columbia, Canada \\ Corresponding Author: gabrielle.lam@ubc.ca
}

\begin{abstract}
Student engagement is believed to be related to students' meaningful learning, persistence and satisfaction. Although its importance is well recognized, student engagement patterns in the virtual learning environment are not well understood, particularly in online courses that offer both synchronous and asynchronous paths. The purpose of this study is to characterize student online engagement in a team-based project-centric course, in terms of behavioral, cognitive, emotional, social and collaborative dimensions. Data from tracking logs and student interviews will be analyzed to elucidate any relationships between the various dimensions of online engagement.
\end{abstract}

Keywords: Online engagement, virtual learning environment, team-based

\section{INTRODUCTION}

\subsection{Study motivation}

Student engagement has become an important focus in the virtual classroom, particularly with the recent pivot to online education in many post-secondary institutions. In massive open online courses, poor completion rates and a decline in participation rates with course progression have been well-documented challenges [1]. This is consistent with observations of other online learning environments, where student attrition is higher than that of in-person learning environments [2].

Although the term "student engagement" is frequently referred to and viewed as desirable for learning, it is often used to encompass multiple meanings. Astin's theory of student involvement was pivotal in paving the way for subsequent research on student engagement. In his work, he defined student involvement as "the quantity and quality of physical and psychological energy that students invest in the college experience", and suggested that it contributes positively to learning [3]. Since then, our understanding of student engagement has grown, with tools such as the National Survey of Student Engagement developed and implemented to assess the degree to which students are involved in educational practices $[4,5]$.

More recently, Kraus expanded the definition of student engagement to encompass the "time, energy, and resources students devote to activities designed to enhance learning" [6]. In addition to its behavioral dimension, which includes student attendance in lectures and participation in learning activities, student engagement has also been described to consist of cognitive and emotional dimensions $[7,8]$. The emotional dimension of engagement refers to students' reactions in their learning environment, while the cognitive dimension of engagement refers to students' investment in learning [8]. Some have proposed that together, these different dimensions of student engagement produce learning, improve persistence and satisfaction [5,9]. By analyzing data stored in tracking logs for three online undergraduate courses, Morris et al. found that final course grades were correlated with frequency and duration of student views of course content and participation in online discussions [10]. At the same time, others have shown no correlation between students' academic performance and their self-reported involvement in autonomous learning activities, including independent course preparation, class participation, and discussions outside of class [11].

Indeed, there have been studies investigating the relationships between the various dimensions of student engagement, and their effects on different student outcomes. However, many of these studies are conducted in the context of asynchronous online courses; less is known about student engagement in team-based online courses with both synchronous and asynchronous paths. 
The purpose of this study is to characterize the extent of student engagement in a team-based technical elective course, and to elucidate any relationships to student persistence.

\subsection{Conceptual framework for online engagement} Many studies of online engagement are based upon three dimensions of cognitive, behavioral and emotional engagement [7,8]. Recently, Redmond and colleagues developed a conceptual framework to describe engagement more comprehensively in the online learning environment; its elements are contended to be crucial to student engagement in an online learning environment [12]. This framework was developed using deductive thematic analyses, and is grounded in a social constructionist perspective, "where asynchronous and synchronous group discussions occur as an intentional way to promote individual and group learning" [12]. For these reasons, it was found to be a suitable framework to study student engagement in a team-based and project-centric technical elective course.

The framework for online engagement developed by Redmond et al. consists of five interconnected elements. In addition to the cognitive, behavioral and emotional dimensions previously mentioned [8], this framework includes social engagement and collaborative engagement dimensions [12]. According to the authors, social engagement refers to students' social investment, as indicated by a sense of community, belonging and established trust, which may be related to academic or nonacademic activities [12]. Collaborative engagement refers to development of relationships that support learning, including those with their peers and with the instructor [12].

\subsection{Significance of results}

By applying the conceptual framework proposed by Redmond and colleagues, this study aims to elucidate patterns in student online engagement in the context of a team-based online course. On one hand, the results will be used to identify dimensions of online engagement that are weakly supported in the course, and which can be bolstered through course design in future iterations. More importantly, the results of this study will highlight any relationships between patterns in student engagement and persistence in online courses.

\section{MethodS}

\subsection{Course structure}

The technical elective course was newly designed for online delivery at the University of British Columbia. At the core of the course was a design project, which students built upon throughout the course by collaborating in a team. The course structure is shown in Figure 1.

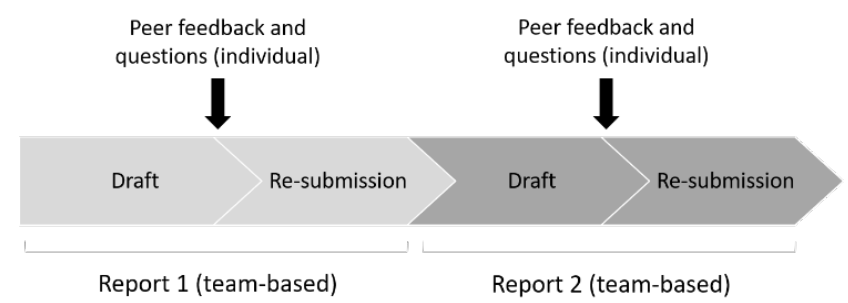

Figure 1. Schematic of the structure for the team-based project-centric online course.

Students compiled two design reports as a team, and created two peer review submissions individually. The first report (Report 1) was submitted for peer review. After receiving multiple peer reviews, the student teams had an opportunity to incorporate suggestions and respond to questions in their report resubmission. This process was repeated again in the last half of the course, with submission and re-submission of Report 2. This course structure, which emphasized collaboration, critical review and response to critical review, was designed to facilitate student development of critical thinking and communication skills.

The course was taken by 33 biomedical engineering undergraduate students from the third- and fourth-year of their program. Of the 33 students in the class, a total of 3 students were located in international time zones (greater than 4-hour time difference). Because peer collaboration was central to the course, teams were assigned to include a mixture of third- and fourth-year undergraduate students, as well as representatives from each of the two technical streams in the undergraduate program.

Students were given the option to engage in the course synchronously or asynchronously. In the synchronous path, students attended online lectures real-time, which provided them the opportunity to interact with peers and the instructor. In the asynchronous path, students reviewed recorded lectures at their own time. Recorded lectures were made available throughout the course, for all students to review and revisit.

\subsection{Data collection and analyses}

In the first stage of the study, data from tracking logs will be analyzed. The duration and frequency of student attendance in synchronous lectures will be traced over time. From these analyses, students will be categorized into three sub-groups, according to their degree of persistence in the course. Additionally, the frequency of student participation in in-class polls and contributions to the live chat will be quantified. 
In the second stage, interviews will be held with student representatives from each sub-group (9 students in total). Students were asked to rate their extent of involvement in each of the five dimensions of online engagement, and to describe the learning activities they were engaged in and that were associated with each dimension. A compilation of the interview questions is provided in the Appendix.

Student responses to interview questions will be analyzed qualitatively by two members in the research team. A transcript of student responses will be obtained, and data will be anonymized prior to analysis. Both members will use an open coding method to approach the content of student responses, labelling instances of behavioral, cognitive, emotional, social and collaborative engagement, as well as the learning activities associated with the course. Student interview responses will be read multiple times to identify key themes. The coders will meet to discuss agreed upon themes, which will be subsequently applied to the final round of coding. Results of these analyses will be synthesized to better understand the interconnections between different dimensions of online engagement.

\section{RESUltS}

The data obtained from tracking logs was analyzed to determine the proportion of total synchronous lecture time attended. To this end, the total duration of time spent in formal lectures throughout the course was calculated for each student. The course consisted of 25 synchronous lectures, with 80 minutes designated per lecture. A histogram of the proportion of total lecture time attended for all students in the course is shown in Figure 2. Based on the histogram below, three subgroups of students were defined: 1) students from the "high participation" subgroup attended more than $80 \%$ of the total lecture time, 2) those from the "moderate participation" subgroup attended between $55-79 \%$ of the total lecture time, and 3) students from the "low participation" subgroup attended less than $54 \%$ of the total lecture time.

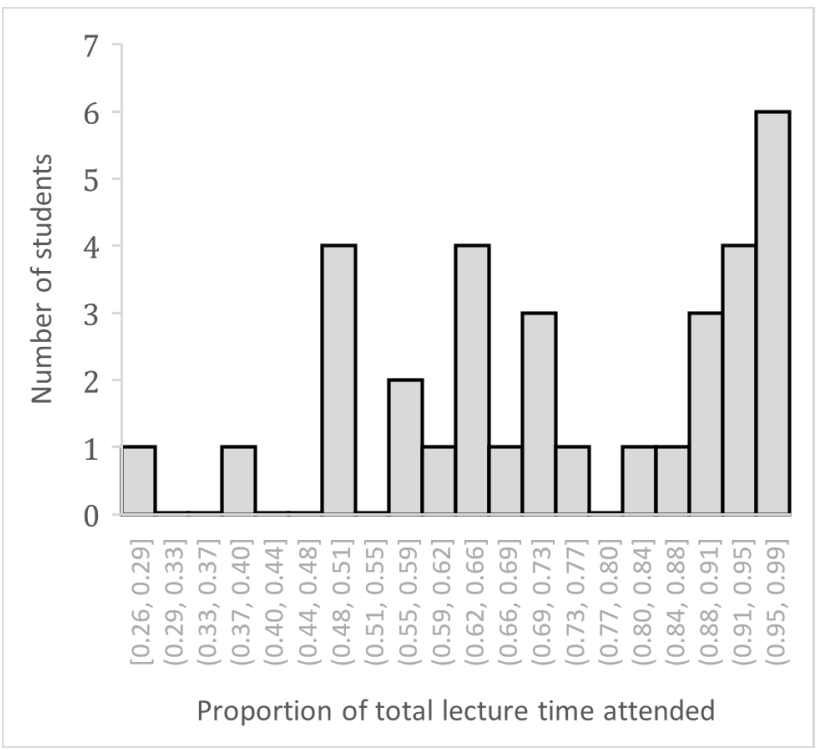

Figure 2. Histogram of proportion of total lecture time attended for all students in the course.

Using student time log data, the average proportion of lecture time attended was tracked throughout the duration of the course (Figure 3).

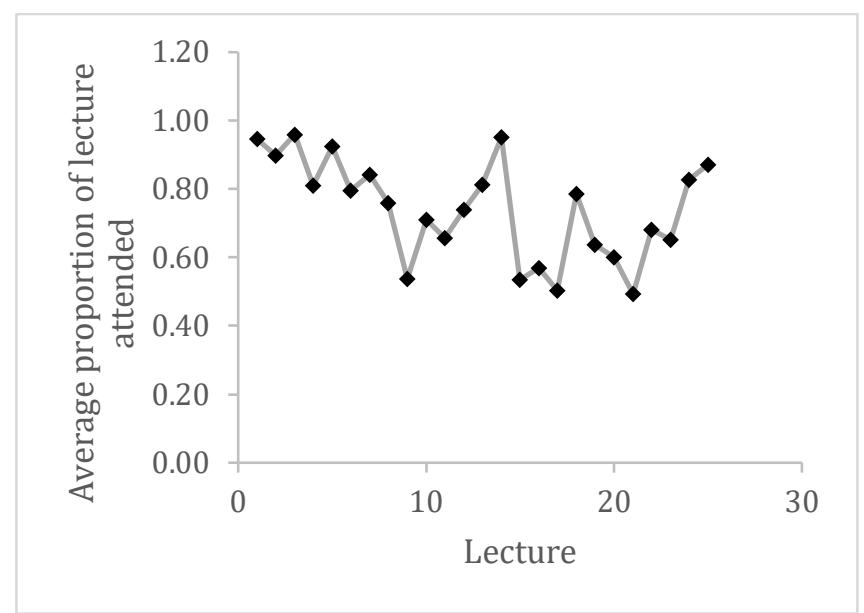

Figure 3. Average proportion of lecture time attended as a function of time.

The data was further subdivided according to the student subgroups defined earlier. There were 15 students in the "high participation" subgroup, 11 in the "moderate participation" subgroup and 6 in the "low participation" subgroup. For each subgroup, the average proportion of lecture time attended was determined, and shown as a function of time (Figure 4). 


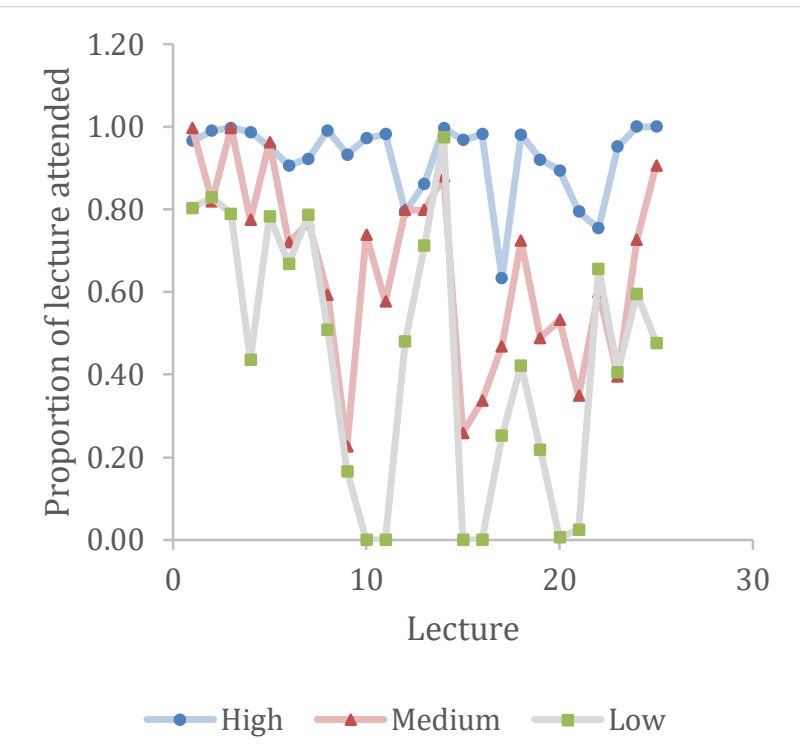

Figure 4. Proportion of synchronous lecture time attended over time, according to student subgroup.

Of the 25 lectures in the course, 6 lectures were used as designated time for students to work within their project teams. In these lectures, 40 of the 80 minutes were assigned as a synchronous team work session, and the remaining time was used to discuss lecture content. The average proportion of team work session time attended was determined for each of the student subgroups, as shown in Figure 5 below.

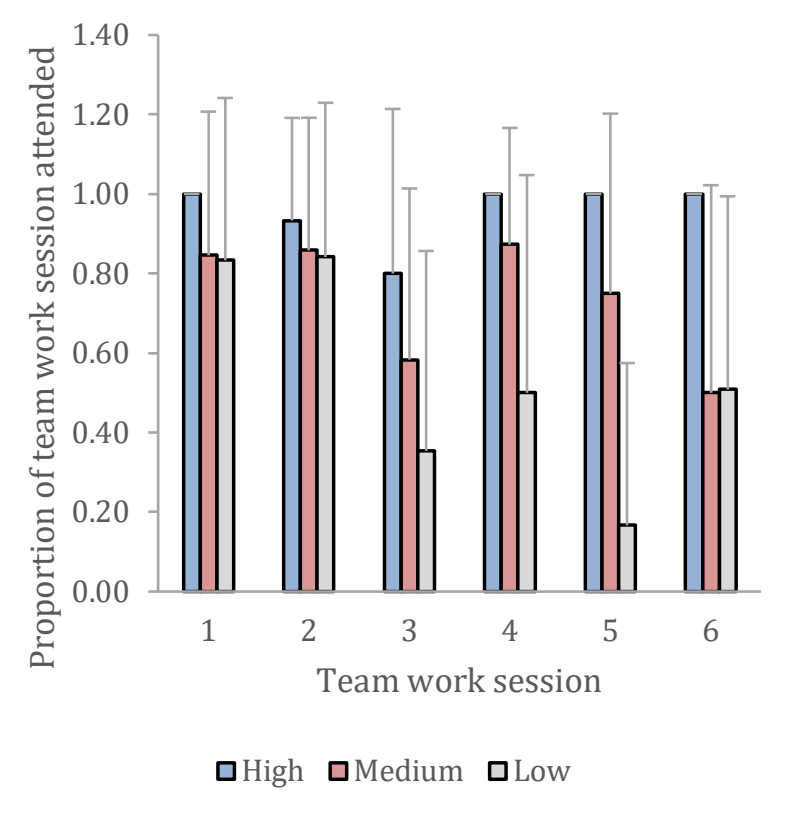

Figure 5. Average proportion of team work session time attended, according to student subgroup.

As part of the student interviews, students were asked to rate their perceived extent of engagement according to the five dimensions of online engagement. Question 1 was associated with social engagement, questions 2 and 3 were associated with cognitive engagement, questions 4 and 5 were associated with behavioral engagement, questions 6 and 7 were associated with collaborative engagement, and questions 8 and 9 were associated with emotional engagement. The average scores for the 9 interviewees are shown in Figure 6.

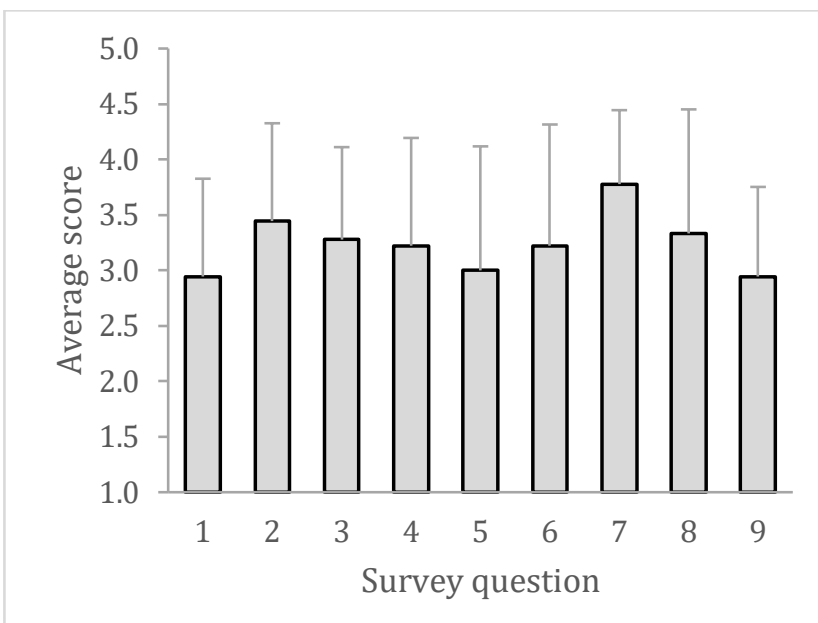

Figure 6. Average scores for students' perceived extent of engagement in each of the five dimensions of online engagement.

\section{DISCUSSION}

Preliminary results show that, based on the proportion of total synchronous lecture time attended in the course, students can be classified according to three subgroups. Interestingly, the number of students in each subgroup is not evenly distributed; a large proportion of students attend over $80 \%$ of the formal lecture time. The remaining students can be subdivided into the "moderate participation" subgroup (12 students) and "low participation" subgroups (6 students). Not surprisingly, 2 of the 3 students located in international time zones were categorized in the "low participation" subgroup.

In tracking the average proportion of lecture time attended by all students throughout the course (Figure 2), results show that attendance decreased to roughly $50 \%$ at a few points in the course. Interestingly, students in the "high participation" subgroup showed greater persistence at these points (Lectures 9, 15-17, and 21) compared to students in the "moderate participation" and "low participation" subgroups. Moreover, students in the "high participation" subgroup showed consistent attendance of team work sessions, sustaining $100 \%$ attendance for 4 of 6 synchronous team work sessions (Figure 5). Students in the "moderation participation" and "low participation" 
subgroups showed a decrease in attendance from the second session onwards.

Quantitative analyses of the preliminary student interview data show that students perceived lowest engagement in the social dimension (Question 1), behavioral dimension (Question 5) and emotional dimension (Question 9). Question 1 is related to students' perceived sense of community in the course, while Question 5 is related to student involvement in peer support. Qualitative analyses of open-ended questions in the interview may elucidate potential reasons for students' responses. It is possible, although not known at this stage, that the virtual learning environment likely contributed to the comparatively low level of engagement in these dimensions of online engagement. Question 9 is related to students' perceived level of commitment to the course. Similarly, qualitative analyses of open-ended questions in the interview will shed light upon potential reasons for student responses.

\section{References}

1. Jung, Y., Lee, J. (2018). Learning engagement and persistence in massive open online courses (MOOCS). Computers and Education, 122: 922.

2. Carr, S. (2000). As distance education comes of age, the challenge is keeping the students. The Chronical of Higher Education, 46: A39-A41.

3. Astin, A. (1985). Achieving educational excellence: A critical assessment of priorities and practices in higher education. San Francisco: Jossey-Bass.

4. Kuh, G., \& Vesper, N. (1997). A comparison of student experiences with good practices in undergraduate education between 1990 and 1994. The Review of Higher Education, 21, 4361.

5. Kuh, G. (2001). Assessing what really matters to student learning: Inside the National Survey of Student Engagement. Change, 33(3): 10-17.

6. Krause, K.-L. (2005). Understanding and promoting student engagement in university learning communities. Retrieved from https://www.liberty.edu/media/3425/teaching_re sources/Stud_eng.pdf

7. Axelson, R.D., Flick, A. (2011). Defining student engagement. Change, 43(1): 38-43.
8. Fredricks, J.A. et al. (2004). School engagement: Potential of the concept, state of the evidence. Review of Educational Research, 74(1), 59-109.

9. Astin, A.W. (1999). Student involvement: A developmental theory for higher education. Journal of College Student Development, 40(5): 518-529.

10. Morris, L.V., et al. (2005). Tracking student behavior, persistence, and achievement in online courses. Internet and Higher Education, 8: 221231.

11. Rabe-Hemp, C., et al. (2009). A comparative analysis of student engagement, learning, and satisfaction in lecture halls and online learning settings. The Quarterly Review of Distance Education, 10(2): 207-218.

12. Redmond, P., et al. (2018). An online engagement framework for higher education. Online Learning, 22(1): 183-204. 


\section{Appendix}

The following table summarizes the survey questions administered to students throughout the course.

Table A1: Summary of survey questions.

\begin{tabular}{|l|l|}
\hline \multicolumn{1}{|c|}{ Dimension } & \multicolumn{1}{c|}{ Question } \\
\hline $\begin{array}{l}\text { Social } \\
\text { engagement }\end{array}$ & $\begin{array}{l}\text { Question 1: To what extent did } \\
\text { you feel a sense of community } \\
\text { in the course? }\end{array}$ \\
\hline $\begin{array}{l}\text { Cognitive } \\
\text { engagement }\end{array}$ & $\begin{array}{l}\text { Question 2: To what extent } \\
\text { were you able to further } \\
\text { develop your critical thinking } \\
\text { skills? } \\
\text { Question 3: To what extent } \\
\text { were you able to develop an } \\
\text { understanding of the principles } \\
\text { governing drug delivery? }\end{array}$ \\
\hline $\begin{array}{l}\text { Behavioral } \\
\text { engagement }\end{array}$ & $\begin{array}{l}\text { Question 4: To what extent did } \\
\text { you develop a sense of } \\
\text { independence as a learner in } \\
\text { the course? }\end{array}$ \\
\hline
\end{tabular}

Question 5: To what extent were you involved in supporting and encouraging your peers?

Collaborative engagement

Question 6: To what extent did you feel as though you were able to relate with the instructor?

Question 7: Which of the following describes your frequency of interaction with the instructor?

Emotional engagement
Question 8: To what extent were you motivated to engage in the course?

Question 9: During the semester, you were juggling multiple courses. To what extent were you committed to engage with the course? 